\title{
Epilepsy in Families: Age at onset is a familial trait, independent of syndrome
}

Running head: Familial epilepsy age at onset

Colin A. Ellis, MD, ${ }^{1,2}$ Leonid Churilov, PhD, ${ }^{3}$ Michael P. Epstein, $\mathrm{PhD},{ }^{4}$ Sharon X. Xie, $\mathrm{PhD},{ }^{5}$ Susannah T. Bellows, MPsych, ${ }^{1}$ Ruth Ottman, PhD, ${ }^{6}$ Samuel F. Berkovic, MD, FRS, ${ }^{1}$ Epi4K Consortium.

\author{
Affiliations: \\ ${ }^{1}$ Epilepsy Research Centre, Department of Medicine, University of Melbourne (Austin \\ Health), Heidelberg, VIC, Australia. \\ ${ }^{2}$ Department of Neurology, University of Pennsylvania Perelman School of Medicine, \\ Philadelphia, PA, USA. \\ ${ }^{3}$ Florey Institute of Neuroscience and Mental Health, Parkville VIC, Australia. \\ ${ }^{4}$ Department of Human Genetics, Emory University, Atlanta, GA, USA. \\ ${ }^{5}$ Department of Biostatistics, Epidemiology and Informatics, University of Pennsylvania, \\ Philadelphia, PA, USA. \\ ${ }^{6}$ Departments of Epidemiology and Neurology, and the G. H. Sergievsky Center, \\ Columbia University; and Division of Translational Epidemiology, New York State \\ Psychiatric \\ Institute, New York, NY, USA.
}

Corresponding author:

Prof. Samuel F. Berkovic, M.D., F.R.S.

Epilepsy Research Centre, L2 Melbourne Brain Centre

245 Burgundy Street

Heidelberg, VIC 3084, Australia.

Tel: +61 90357093

Fax: +6194962291

Email: epi4k-fam@unimelb.edu.au

Title characters: 79

Running head characters: 30

Abstract word count: 249

Total body word count: 3,691

Introduction word count: 314

Discussion word count: 1,409

References: 36

Tables: 3

Figures: 2

This is the author manuscript accepted for publication and has undergone full peer review but has not been through the copyediting, typesetting, pagination and proofreading process, which may lead to differences between this version and the Version of Record. Please cite this article as doi: 10.1002/ana.25499

This article is protected by copyright. All rights reserved. 
Color Figures: 1

Familial epilepsy age at onset - 2

This article is protected by copyright. All rights reserved. 


\section{ABSTRACT}

Objective: We tested two hypotheses regarding age at onset within familial epilepsies: (1) family members with epilepsy tend to have similar ages at onset, independent of epilepsy syndrome; (2) age at onset is younger in successive generations after controlling for sampling bias.

Methods: We analyzed clinical data collected by the Epi4K Consortium (303 multiplex families, 1,120 individuals). To test hypothesis 1 , we used both linear mixed models commonly used for heritability analysis and Cox regression models with frailty terms to assess clustering of onset within families after controlling for other predictors. To test hypothesis 2, we used mixed effects models, pair-wise analyses, and survival analysis to address sampling-related bias that may mimic anticipation.

Results: (1) Age at seizure onset was significantly heritable (ICC 0.17, p < 0.001) after adjusting for epilepsy type, sex, site, history of febrile seizure, and age at last observation. This finding remained significant after adjusting for epilepsy syndromes, and was robust across statistical methods in all families and in generalized families. (2) The mean age at onset decreased in successive generations $(p<0.001)$. After adjusting for age at last observation, this effect was not significant in mixed-effects models $(\mathrm{p}=0.14)$, but remained significant in pair-wise $(\mathrm{p}=0.0003)$ and survival analyses $(\mathrm{p}=0.02)$.

Interpretation: Age at seizure onset is an independent familial trait, and may have genetic determinants distinct from the determinants of particular epilepsy syndromes. Younger onsets in successive generations can be explained in part by sampling bias, but the presence of genetic anticipation cannot be excluded. 


\section{INTRODUCTION}

Epilepsy is a disorder with strong genetic contributions. Relatives of people with epilepsy have an increased incidence of epilepsy, even in families without Mendelian (monogenic) patterns of inheritance. ${ }^{1,2}$ Moreover, studies of twins and families have shown that specific features of epilepsy are themselves heritable traits, including specific epilepsy syndromes, ${ }^{3,4}$ seizure types and symptoms, ${ }^{5,6}$ and EEG patterns. ${ }^{7-9}$ These features may have genetic determinants that are distinct from the genetic determinants of epilepsy per se.

Age at epilepsy onset is variable across individuals, even those with the same epilepsy syndrome. ${ }^{10-12}$ Whether this variability in age at onset is (at least in part) genetically determined remains unknown. In this study, using data from a large cohort of multiplex families with epilepsy, ${ }^{13}$ we hypothesized that age at epilepsy onset is in part a heritable trait. This analysis must account for epilepsy syndromes, which often have characteristic ages of onset and which tend to aggregate in families. Thus, family members might have similar ages of onset because they share the same syndrome. If, however, family members have similar ages of onset after adjusting for epilepsy syndrome, this would suggest that age at onset is itself heritable.

In a separate analysis, we observed in these families that age at onset tends to decrease across successive generations. This effect may be due to anticipation, a known genetic phenomenon, or may be a spurious finding due to sampling-related bias. ${ }^{14-19}$ For example, early ages of onset may be over-represented in later generations because they are younger at the time of the study; conversely, older ages of onset may be over-represented in older generations because childhood epilepsies that have long-since resolved may be 
forgotten and not ascertained. We sought to determine whether these forms of sampling bias are present in our data and, if so, whether they completely account for the observed association between generation and age at epilepsy onset.

\section{METHODS}

\section{Data Collection}

Ascertainment methods and data collection have been described in detail. ${ }^{13}$ Briefly, each family contained three or more relatives with unprovoked seizures. Relatives with epilepsies of known acquired causes, such as structural brain lesions, were not included. Once a family was ascertained, data on every affected relative were obtained by direct interview, sourcing of available records or by interviewing reliably family informants. Ascertainment and data collection took place at 7 centers in North America, Europe, Australia and New Zealand, and has occurred gradually at each center over many years. For the Epi4K study, all data were systematically reviewed, entered into a detailed database, and cross-validated by study personnel at multiple sites. Families with known causal mutations were excluded.

During this review process, each individual was assigned to one of five epilepsy types (generalized, focal, combined generalized/focal, febrile seizures plus (FS+), or unknown) by an expert clinician. Those individuals with generalized or focal epilepsy were further assigned to epilepsy subtypes, including recognized epilepsy syndromes. ${ }^{20}$ The subtypes of generalized epilepsy were early onset absence epilepsy, childhood absence epilepsy, juvenile absence epilepsy, childhood/juvenile absence epilepsy indistinguishable, juvenile myoclonic 
epilepsy, generalized tonic-clonic seizures alone, “severe” generalized epilepsy (including myoclonic atonic epilepsy, absence epilepsy with eyelid myoclonia, myoclonic absence epilepsy, and one case of Lennox-Gastaut syndrome of unknown cause) and other generalized epilepsy. The subtypes of focal epilepsy were temporal lobe epilepsy, frontal lobe epilepsy, posterior quadrant epilepsy (including parietal and occipital lobes), self-limited focal epilepsy of childhood, and unlocalized focal epilepsy. After epilepsy types and subtypes were assigned to individuals, each family was assigned to one of four categories (generalized, focal, generalized epilepsy with febrile seizures plus (GEFS+), or mixed) as previously described. $^{13}$

Age at epilepsy onset was defined as the age at first unprovoked seizure. Provoked seizures and febrile seizures were not included in this definition. Age at last observation was the age at the time of direct interview, informant interview, or last medical documentation available for review, whichever was last. For all family members, this reflects the end of an age window beyond which the subject could not have been observed to have onset of epilepsy. In a few cases where information about a subject was collected after his or her death, by interview of family members, we defined the last observation as the age of death. Generations within each pedigree were counted relative to the youngest generation, to account for pedigrees of various sizes across the cohort. Information about age was not collected for family members without epilepsy.

The Epi4K study was approved by the research ethics committee at each participating site and all subjects provided informed consent to participate. The current analysis used only deidentified data from that study, therefore separate ethics approval was not required. 


\section{Statistical Analysis}

We conducted two sets of analyses, testing two distinct hypotheses: (1) that age at epilepsy onset correlates within families after accounting for other predictors, suggesting age at onset is a heritable trait; (2) that age at onset is younger in successive generations after controlling for sampling biases, suggesting that genetic anticipation may be present.

To test hypothesis 1 , we constructed linear mixed effects models that modeled the known contributors as fixed effects and shared familial effects as random effects. To model random familial effects, we took the standard approach and assumed such effects followed a multivariate normal distribution with mean vector 0 and covariance matrix equivalent to twice the kinship matrix multiplied by the estimated variance due to polygenes. Fixed effects included sex, ascertainment site, history of febrile seizure, epilepsy type, and age at last observation. The fixed effect “epilepsy type” was first defined broadly for each individual (generalized, focal, combined, FS+, unknown). In separate models including only those families with generalized or focal epilepsies, we also included the applicable epilepsy subtypes or syndromes as fixed effects. Prior to analysis, we performed an inverse-normal transformation on age at onset to satisfy the assumptions of linear mixed effects models (repeating the analysis with untransformed age at onset values produced a qualitatively similar pattern of results).

Intraclass correlation coefficients (ICC) calculated from these mixed effects models were estimates of the proportion of variability in age at onset that is attributable to shared familial effects after first adjusting for the fixed effect variables. We tested the significance of 
the shared familial effects using a likelihood-ratio statistic, which compared the full model that included the random familial effect with the null model that excluded the random familial effect. Collinearity among independent variables was evaluated by variance inflation factor method and was not substantially present in the models.

As an alternative approach to testing hypothesis 1, we also performed a Cox proportional hazard (survival) analysis that accounted for right truncation of the distribution of onset ages, which must be less than age at last observation. We first reversed the time axis to convert right truncation into left truncation. ${ }^{21,22}$ We then constructed Cox proportional hazard models using the same fixed effects as the mixed-effects model above while modelling the random (shared) family effects using a frailty term following a gamma distribution. The significance of the shared-frailty term in these models tests the hypothesis that age at onset aggregates within families, while adjusting for the covariates and truncation bias.

To test hypothesis 2, we performed a series of analyses aimed at distinguishing the relative contributions of sampling bias versus genetic anticipation in producing younger onsets over successive generations within families. First, for the entire cohort, we constructed a mixed-effects model using age at onset as the outcome variable, generation as the independent variable (fixed effect), and family as a random effect. We then added age at last observation as an additional fixed-effect independent variable, and assessed the relative contributions of generation versus age at last observation as predictors of age at onset.

Next, following studies exploring anticipation versus sampling bias in other disorders, ${ }^{15-17}$ we identified affected parent-child pairs for further analysis. We included only 
one nuclear family per pedigree; following the procedure of Tsai et al ${ }^{16}$ we selected the largest nuclear family within each pedigree or, in case of ties, randomly selected one nuclear family per pedigree. To test whether children have earlier onset than parents while accounting for multiple affected parent-child pairs within families, we used a mixed-effect models to regress delta age at onset (i.e., Onset $_{\text {parent }}-$ Onset $_{\text {child }}$ ) on the model intercept, treating family as random effect. We repeated these pairwise analyses in the subset of “comparable” parent-child pairs, ${ }^{15,16}$ being those pairs in which both members’ age at last observation was older than both members' age at onset. Conceptually, this excludes pairs in which the parent's seizure onset occurs at an older age than the child was ascertained or last observed, because in that circumstance the child's onset can only be earlier than the parent's. This approach reduces bias due to right truncation, although it does so with some limitations and does not reduce other kinds of bias (see Discussion).

Finally, we repeated the Cox proportional hazards model with frailty terms in all families as described above, adding generation to the model as a covariate. The significance of this generation term in the model tests the association between generation and age at onset while adjusting for other fixed effects, familial aggregation, and truncation bias.

Analyses were performed using Stata and the $\mathrm{R}$ programming language. The $\mathrm{R}$ packages Kinship2 and FamAgg were used for pedigree analysis. Mixed-effects modeling was carried out in Stata and in R using the Imekin function within the coxme package. Survival analyses were performed in R using the survival package.

\section{RESULTS}




\section{Clinical characteristics}

The characteristics of this cohort have been described in detail. ${ }^{13}$ In summary, the cohort includes 1,120 individuals with epilepsy from 303 families. Families contained 3-8 affected individuals. Age at epilepsy onset was available for 1,064 subjects (Table 1), and complete data were available for 1,008 subjects from 300 families. The distribution of age at onset was skewed, with many childhood onset cases and relatively fewer adult onset cases, consistent with the known epidemiology of familial epilepsies. ${ }^{2}$ Focal epilepsy subtypes had more variability in age at onset compared to generalized epilepsy subtypes, as expected.

\section{Correlation of age at onset within families}

Mixed effects models showed a significant correlation among family members’ ages of onset after adjusting for sex, ascertainment site, history of febrile seizure, epilepsy type, and age at last observation (Table 2). The results were similar when the analysis was carried out within strata defined by broad family epilepsy type (generalized families and focal families). When the stratified analysis was repeated with additional adjustment for the epilepsy subtypes and syndromes of the individual subjects (listed in Methods and in Table 1), the magnitude of the ICC decreased, suggesting that some of the familial correlation in age at onset is explained by familial clustering of these subtypes. Nonetheless, these models still demonstrated a significant family contribution to age at onset after adjusting for familial aggregation of epilepsy syndromes and subtypes.

We also performed shared-frailty survival analysis to account explicitly for right truncation of our observed distribution of age at onset. Testing the variance of the family- 
based frailty term, we continued to observe significant evidence of familial correlation of age of onset in all families (variance $=0.17, \mathrm{X}^{2}(102)=183.6, \mathrm{p}<0.001$ ) and generalized families (variance $\left.=0.24, \mathrm{X}^{2}(38)=71.5, \mathrm{p}<0.001\right)$ after adjustment for syndromes. However, after adjustment for syndrome, familial correlation in focal families did not reach significance (variance $=0.10, \mathrm{X}^{2}(11)=16.6, \mathrm{p}=0.11$ ).

\section{Earlier onset in successive generations}

We observed in these data that younger generations had earlier age at onset compared to older generations (Figure 1A). To explore qualitatively the contribution of sampling bias to this observed association, we plotted age at last observation versus age at epilepsy onset (Figure 1B) which demonstrated evidence for two sources of bias. First, age at onset logically cannot be greater than age at last observation (creating the diagonal “ceiling” effect in the plot), so subjects with young ages at last observation must by definition have young ages at onset. Second, among subjects with older ages at last observation, young ages at onset are relatively under-represented. Because age at last observation is strongly related to generation (colors in Figure 1B), these two sampling-related effects contribute to the observed association between generation and age at onset.

We tested the association between generation and age at onset in a simple mixedeffects model, using family as a random effect to account for relatedness. Generation was significantly associated with age at onset (slope estimate 6.2, 95\% CI 5.0, 7.4, $p<0.001$ ). When age at last observation was added to the model as a second predictor of age at onset, generation was no longer significantly associated with age at onset (slope estimate -1.3, 95\% 
CI -3.1, 0.3, $p=0.14$ ), whereas age at last observation was significantly associated with age at onset (slope estimate 0.32, 95\% CI 0.27, 0.36, $p<0.001$ ). These slope estimates indicate change in age at onset (in years) per one unit change in the predictor variable.

Next, we performed pairwise analysis of affected parent-child pairs, using analyses that selected one nuclear family per pedigree and adjusted for multiple pairs within families (Table 3). In all eligible pairs the mean difference in age at onset between parent and child was 6.4 years (95\% CI 4.6, 8.2). When we repeated these analyses in only “comparable” parent-child pairs, the mean difference in age at onset between parent and child was reduced to 2.3 years $(95 \%$ CI $1.0,3.5)$ but this difference was still significantly greater than zero $(p=$ 0.0003).

Finally, we repeated the survival analysis in all families, adding generation as a covariate. The generation term was significantly associated with age at onset $(\mathrm{X} 2(1)=5.1$, p $=0.02$ ) despite adjusting for other covariates, familial aggregation, and truncation bias.

\section{DISCUSSION}

In this study, using data from a large cohort of families with common epilepsies, we tested two hypotheses related to age at epilepsy onset within families. First, we tested whether age at onset aggregates within families. The results indicated significant correlation of age at onset within families after controlling for multiple potential predictors of age at onset, including epilepsy types (e.g. generalized or focal) and more specific epilepsy subtypes and syndromes (e.g. absence epilepsies, juvenile myoclonic epilepsy). The findings suggest that age at onset has familial determinants, independent of epilepsy syndrome. Second, we 
tested whether age at onset decreases in successive generations. We found that much of this effect disappeared after controlling for sampling bias, but some evidence for declining age remained, suggesting a role for genetic anticipation in at least some families.

In testing the hypothesis that age at onset correlates within families, it was particularly important to account for epilepsy syndromes. Some syndromes have characteristic ages at onset (e.g. childhood absence epilepsy; juvenile myoclonic epilepsy), and these syndromes tend to aggregate within families, so correlation of age at onset within families could be partly explained by familial aggregation of these syndromes. We found that family membership explains a significant portion of the variability of age at onset after accounting for epilepsy syndromes. Conceptually, this implies that among families with a given syndrome (e.g. JME), some will tend to have onset at a younger age (e.g. 12 years) while others will tend to have onset at an older age (e.g. 18 years), and this age at onset is a heritable feature of each family's epilepsy, independent of the syndrome they share. This finding was robust to multiple statistical approaches in the generalized epilepsies; in the focal epilepsies the effect was smaller, and in one statistical approach did not reach statistical significance. We note that decreasing age at onset in successive generations, while not incompatible with familial aggregation, tends to make family members’ onset ages less similar to one another. To the extent that this generational effect is an artifact of sampling bias (see below), our estimates of intrafamilial aggregation may underestimate the true heritability of age at onset.

Prior literature has hinted at the familial nature of age at epilepsy onset. For example, a study of twins with febrile convulsions found a correlation in their ages at onset. ${ }^{23}$ A study 
of families with genetic generalized epilepsy (formerly idiopathic generalized epilepsy) found that age at onset tends to cluster within families, but the analysis did not account for other predictors of age at onset and the authors acknowledged that shared epilepsy syndromes within families may have explained their observation. ${ }^{24}$ Age at onset is a heritable trait in other familial neurocognitive disorders, including major depressive disorder, ${ }^{26}$ essential tremor, ${ }^{27}$ and frontotemporal dementia, ${ }^{28}$ but this effect has not previously been fully explored in epilepsy.

Our findings suggest that age at seizure onset may be determined at least in part by genetic factors, and that these genetic determinants may be distinct from the genetic factors that lead to the development of epilepsy per se. The nature of these genetic determinants is presently unknown. One possibility is that the genetic factors that determine the time course and trajectory of neurodevelopment (including the maturation of neuronal networks, changes in the expression of different ion channel subunits, etc.) interact with the genetic factors that cause (or confer risk of) epilepsy. Under this model, age at seizure onset likely reflects the interaction of these overlapping but distinct processes and their respective genetic determinants. A less likely possibility is that age at seizure onset has its own set of genetic determinants, independent of the genetic determinants of epilepsy. Future studies will be needed to better understand the mechanisms of these complex processes.

These observations are relevant to syndrome diagnosis and definitions. Age at onset is considered a crucial piece of data in diagnosing some syndromes, particularly in childhood and adolescence, and in defining the nosological boundaries of those syndromes. For example, there are arguments as to whether one can diagnose juvenile myoclonic epilepsy in 
a nine-year-old or a 22-year-old, when the syndrome is classically regarded as beginning between 12 and 18 years. ${ }^{29,30}$ The distinction between childhood absence epilepsy (typical onset 4-8 years) and juvenile absence epilepsy (typical onset 12-18 years) can be blurred when patients present between these typical ages. Our finding that age at epilepsy onset is determined in part by familial factors independent of epilepsy syndromes sheds light on this debate, and argues for looser rather than tighter age-based definitions.

In our second analysis, we observed that successive generations within these families tended to have earlier ages at onset. This raises the possibility of anticipation, a well-known genetic phenomenon. Anticipation has previously been suggested in families with epilepsy. ${ }^{31}$ Repeat expansions, the best known mechanism of anticipation, ${ }^{32,33}$ are not common causes of epilepsy, but were recently identified as the mechanism of benign adult familial myoclonic epilepsy, ${ }^{34}$ and may be a more common mechanism of epilepsy than previously thought. Parental mosaicism, another potential cause of anticipation, ${ }^{35}$ is common in severe pediatric epilepsies $^{36}$ and could also be present in milder forms of epilepsy. Additional mechanisms of anticipation may be yet undiscovered.

However, the appearance of anticipation may also be a spurious finding due to various forms of bias: ${ }^{14-19}$ (1) later onset ages will be underrepresented in the youngest generation, who are ascertained at young ages; (2) early onset epilepsies will be underrepresented among older generations, due to reduced reproductive fitness in severe cases or the resolution of mild childhood epilepsies; (3) ascertainment of multiplex families may be biased toward families with adult onset epilepsies in parents and childhood onset epilepsies in offspring, rather than the reverse (see Figure 2); (4) parents with subtle seizure 
types (e.g. absence) may recognize these seizures earlier in their children than they were recognized in the parents themselves.

We found evidence of bias within our data (see Figure 1 and accompanying text) and used several statistical approaches to address it. Analysis of “comparable” parent-child pairs ${ }^{15,16}$ reduced (but did not eliminate) a significant difference in onset ages between parents and children. Separately, a survival analysis adjusting for right truncation showed a significant association between generation and age at onset. These approaches address right truncation caused by ascertainment of children at younger ages than their parents, but they do not address other forms of bias. On balance, our interpretation is that the generation effect observed across this large cohort results largely from sampling-related bias, but the presence of anticipation in some families with epilepsy remains possible. The search for a possible mechanism, such as the recently shown repeat expansion in benign adult familial myoclonic epilepsy, ${ }^{34}$ may be worthwhile.

Our study has several limitations. Ascertainment of families occurred over time and retrospectively. Subjects' memories of the age at which their epilepsy began may have been inaccurate. We attempted to collect medical records wherever possible, but these were not always available. Similarly, assignment of epilepsy types and subtypes was based on all available information about seizure types and EEG findings, but this information was sometimes limited and some patients could not be confidently classified. Retrospective ascertainment also creates the potential for biases that may lead to spurious findings. ${ }^{25}$ We have attempted to control for these biases in several ways: with mixed-effects models that adjust for age at last observation; with survival models that adjust for right truncation; and 
with pairwise analyses limited to comparable pairs. However, bias is best addressed through study design, and our findings should be confirmed by prospective studies that ascertain and follow both affected and at risk individuals over time, rather than through retrospective ascertainment of affected cases. Finally, while we cannot exclude the possibility that shared environmental (rather than genetic) factors contributed to similar ages at onset within families, this seems unlikely to be the major cause of our findings because there are no known environmental determinants of age at epilepsy onset and because the familial effect was present at every site of ascertainment.

In conclusion, our findings suggest that age at seizure onset is a familial trait, independent of epilepsy syndrome, and may have genetic determinants that are distinct from the genetic determinants of epilepsy per se. An apparent anticipation effect in these data is due largely to sampling bias, although anticipation may exist in some families with epilepsy. Future studies should confirm these findings and seek to clarify the underlying mechanisms that determine the age at which epilepsy occurs. 


\section{Acknowledgements:}

We thank all individuals, including patients and their families, who participated in the study, as well as the clinicians and research staff at many institutions who contributed to the study.

The Epi4K family study was supported by an NINDS National Institute of Health grant (ID: U01NS077367). S.F.B. was supported by an NHMRC Program Grant (ID:

628952). R.O. was supported by NIH grants R01 NS078419 and P50 HG007257. M.P.E. was supported by NIH grant R01 GM117946. C.A.E. was supported in part by a Ruth L.

Kirschstein National Research Service Award (NRSA) Institutional Research Training Grant, T32 NS091008-01. S.X.X. is supported by NIH grant R01-NS102324.

\section{Author Contributions:}

C.A.E. and S.F.B. contributed to study concept and design. C.A.E., L.C., M.P.E., S.X.X., S.T.B., R.O., S.F.B., and the Epi4K Consortium contributed to data acquisition and analysis. C.A.E., M.P.E., R.O., S.T.B., and S.F.B contributed to drafting of the manuscript and figures.

Potential Conflicts of Interest:

Nothing to report. 


\section{REFERENCES}

1. Annegers JF, Hauser WA, Anderson VE, Kurland LT. The risks of seizure disorders among relatives of patients with childhood onset epilepsy. Neurology 1982;32(2):1749.

2. Peljto AL, Barker-Cummings C, Vasoli VM, et al. Familial risk of epilepsy: a population-based study. Brain 2014;137(3):795-805.

3. Berkovic SF, Howell RA, Hay DA, Hopper JL. Epilepsies in twins: Genetics of the major epilepsy syndromes. Ann. Neurol. 1998;43(4):435-445.

4. Vadlamudi L, Milne RL, Lawrence K, et al. Genetics of epilepsy: The testimony of twins in the molecular era. Neurology 2014;83(12):1042-8.

5. Winawer MR, Marini C, Grinton BE, et al. Familial clustering of seizure types within the idiopathic generalized epilepsies. Neurology 2005;65(4):523-528.

6. Tobochnik S, Fahlstrom R, Shain C, et al. Familial aggregation of focal seizure semiology in the Epilepsy Phenome/Genome Project. Neurology 2017;89(1):22-28.

7. Metrakos K, Metrakos JD. Genetics of convulsive disorders. II. Genetic and electroencephalographic studies in centrencephalic epilepsy. Neurology 1961;11:47483.

8. van Beijsterveldt CE, Molenaar PC, de Geus EJ, Boomsma DI. Heritability of human brain functioning as assessed by electroencephalography. Am. J. Hum. Genet. 1996;58(3):562-73.

9. Waltz S, Stephani U. Inheritance of Photosensitivity. Neuropediatrics 2000;31(2):8285.

10. Roger J, Bureau M, Dravet C, Genton P, Tassinari CA WP, editor. Epileptic syndromes in infancy, childhood and adolescence. 4th Editio. London: John Libbey Eurotext; 2005.

11. Jallon P, Latour P. Epidemiology of Idiopathic Generalized Epilepsies. Epilepsia 2005;46(s9):10-14.

12. Reichsoellner J, Larch J, Unterberger I, et al. Idiopathic generalised epilepsy of late onset: a separate nosological entity? J. Neurol. Neurosurg. Psychiatry 2010;81(11):1218-22.

13. Epi4K Consortium. Phenotypic analysis of 303 multiplex families with common epilepsies. Brain 2017;140(8):2144-2156.

14. Hodge SE, Wickramaratne P. Statistical pitfalls in detecting age-of-onset anticipation: the role of correlation in studying anticipation and detecting ascertainment bias. Psychiatr. Genet. 1995;5(1):43-7.

15. Rabinowitz D, Yang Q. Testing for age-at-onset anticipation with affected parent-child pairs. Biometrics 1999;55(3):834-8.

16. Tsai WY, Heiman GA, Hodge SE. New simple tests for age-at-onset anticipation: application to panic disorder. Genet. Epidemiol. 2005;28(3):256-60.

17. Boonstra PS, Gruber SB, Raymond VM, et al. A review of statistical methods for testing genetic anticipation: looking for an answer in Lynch syndrome. Genet. Epidemiol. 2010;34(7):756-68.

18. Fraser FC. Trinucleotide repeats not the only cause of anticipation. Lancet 
1997;350(9076):459-460.

19. Vieland VJ, Huang J. Statistical evaluation of age-at-onset anticipation: a new test and evaluation of its behavior in realistic applications. Am. J. Hum. Genet. 1998;62(5):1212-27.

20. Scheffer IE, Berkovic S, Capovilla G, et al. ILAE classification of the epilepsies: Position paper of the ILAE Commission for Classification and Terminology. Epilepsia 2017;58(4):512-521.

21. Klein JP, Moeschberger ML. Survival Analysis : Techniques for Censored and Truncated Data. 2nd Edition. New York: Springer; 2003.

22. Austin PC. A Tutorial on Multilevel Survival Analysis: Methods, Models and Applications. Int. Stat. Rev. 2017;85(2):185-203.

23. Tsuboi T, Endo S. Genetic studies of febrile convulsions: analysis of twin and family data. Epilepsy Res. Suppl. 1991;4:119-28.

24. Kinirons P, Rabinowitz D, Gravel M, et al. Phenotypic concordance in 70 families with IGE-implications for genetic studies of epilepsy. Epilepsy Res. 2008;82(1):2128.

25. Minikel EV, Zerr I, Collins SJ, et al. Ascertainment bias causes false signal of anticipation in genetic prion disease. Am. J. Hum. Genet. 2014;95(4):371-82.

26. Ferentinos P, Koukounari A, Power R, et al. Familiality and SNP heritability of age at onset and episodicity in major depressive disorder. Psychol. Med. 2015;45(10):221525.

27. Louis ED, Hernandez N, Rabinowitz D, et al. Predicting age of onset in familial essential tremor: how much does age of onset run in families? Neuroepidemiology 2013;40(4):269-73.

28. Barbier M, Camuzat A, Houot M, et al. Factors influencing the age at onset in familial frontotemporal lobar dementia: Important weight of genetics. Neurol. Genet. 2017;3(6):e203.

29. Janz D. Epilepsy with impulsive petit mal (juvenile myoclonic epilepsy). Acta Neurol. Scand. 1985;72(5):449-59.

30. Kasteleijn-Nolst Trenité DGA, Schmitz B, Janz D, et al. Consensus on diagnosis and management of JME: From founder's observations to current trends. Epilepsy Behav. 2013;28 Suppl 1:S87-90.

31. Cvetkovska E, Panov S. Possible genetic anticipation in families with idiopathic generalised epilepsy. Epileptic Disord. 2011;13(2):150-4.

32. Sutherland GR, Haan EA, Kremer E, et al. Hereditary unstable DNA: a new explanation for some old genetic questions? Lancet 1991;338(8762):289-92.

33. Lindblad K, Schalling M. Expanded Repeat Sequences and Disease. Semin. Neurol. 1999;19(03):289-299.

34. Ishiura H, Doi K, Mitsui J, et al. Expansions of intronic TTTCA and TTTTA repeats in benign adult familial myoclonic epilepsy. Nat. Genet. 2018;50(4):581-590.

35. Donkervoort S, Hu Y, Stojkovic T, et al. Mosaicism for dominant collagen 6 mutations as a cause for intrafamilial phenotypic variability. Hum. Mutat. 2015;36(1):48-56.

36. Myers CT, Hollingsworth G, Muir AM, et al. Parental Mosaicism in "De Novo" Epileptic Encephalopathies. N. Engl. J. Med. 2018;378(17):1646-1648. 


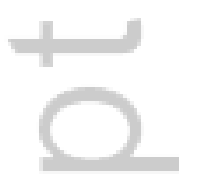




\section{FIGURE LEGENDS}

Figure 1. (A) Age at onset was significantly associated with generation, with earlier onset in younger generations (Spearman rho $=-0.31, p<0.001$ ). (B) Age at last observation reveals evidence of several sources of bias that may explain the generation effect in panel (A). Younger generations were ascertained at younger ages, and thus only early ages of onset were captured. Older generations were ascertained at older ages and early ages of onset were under-represented.

Figure 2. Two hypothetical pedigrees, with ages at epilepsy onset in years. Family A will be easily recognized and ascertained as multiplex because the parent is affected as an adult and the offspring are affected as children, making it likely they will all be affected concurrently and while living as a nuclear family. Family B will be less easily recognized and ascertained as multiplex, because the parent's childhood onset epilepsy may have resolved by the time the offspring present with seizures in adulthood. This is one form of bias that can lead to a spurious appearance of anticipation. . $^{7,19}$ 
Table 1. Descriptive statistics, age at onset by epilepsy type.

\begin{tabular}{|c|c|c|c|c|}
\hline \multirow[b]{2}{*}{ Epilepsy Type/Subtype } & \multirow[b]{2}{*}{$\mathrm{n}$} & \multicolumn{3}{|c|}{ Age at onset (yrs) } \\
\hline & & Mean $( \pm S D)$ & Median & Range \\
\hline Generalized & 492 & $9.5( \pm 6.3)$ & 9 & $0.1-40$ \\
\hline - Early onset absence & 63 & $2.1( \pm 0.8)$ & 2 & $0.6-3$ \\
\hline - Childhood absence (CAE) & 106 & $6.0( \pm 1.8)$ & 6 & $1.5-8$ \\
\hline - CAE/JAE indistinguishable ${ }^{a}$ & 44 & $10.0( \pm 1.4)$ & 10 & $3-13$ \\
\hline - Juvenile absence (JAE) & 36 & $13.8( \pm 2.0)$ & 13.5 & $10-18$ \\
\hline - Juvenile myoclonic & 111 & $14.6( \pm 2.8)$ & 14 & $9-24$ \\
\hline - Generalized tonic-clonic alone & 31 & $13.7( \pm 3.7)$ & 14 & $7-23$ \\
\hline - Severe generalized & 24 & $2.9( \pm 2.1)$ & 2 & $0.8-8$ \\
\hline - Other generalized & 77 & $11.2(10.0)$ & 8 & $0.1-40$ \\
\hline Focal & 313 & $13.8( \pm 11.7)$ & 11 & $0.1-84$ \\
\hline - Temporal & 128 & $18.1( \pm 12.5)$ & 15 & $0.5-84$ \\
\hline - Frontal & 27 & $9.6( \pm 8.5)$ & 6 & $0.5-37$ \\
\hline - Posterior quadrant & 64 & $10.9( \pm 7.2)$ & 10.5 & $0.3-30$ \\
\hline - Self-limited focal epilepsy & 43 & $6.3( \pm 2.8)$ & 6 & $1.3-15$ \\
\hline - Unlocalized & 51 & $15.2(15.4)$ & 12 & $0.1-68$ \\
\hline Combined generalized/focal & 61 & $8.3( \pm 6.6)$ & 7 & $0.1-35$ \\
\hline Febrile seizures plus & 16 & $4.9( \pm 3.3)$ & 5 & $0.1-7$ \\
\hline Unknown epilepsy type & 182 & $15.9( \pm 12.2)$ & 14 & $0.1-80$ \\
\hline Total & 1,064 & $11.7( \pm 9.7)$ & 10 & $0.1-84$ \\
\hline
\end{tabular}

${ }^{a}$ A few participants with otherwise typical onset ages of CAE and CAE/JAE overlap had single unprovoked tonic-clonic seizures at younger ages and this initial seizure age was taken as age at onset. 
Table 2. Results of mixed effects models, testing for correlation of age at onset within families after adjusting for epilepsy type, sex, ascertainment site, history of febrile seizure, and age at last observation.

Abbreviations: ICC, intraclass correlation coefficient.

\begin{tabular}{|c|c|c|c|}
\hline Model & $\begin{array}{l}\mathrm{N} \text { of individuals } \\
\text { (families) }\end{array}$ & ICC & p-value ${ }^{a}$ \\
\hline All families & $1,008(300)$ & 0.17 & $<0.001$ \\
\hline Generalized families & $373(115)$ & 0.29 & $<0.001$ \\
\hline - Additional adjustment for subtype/syndrome ${ }^{\mathrm{b}}$ & & 0.11 & 0.02 \\
\hline Focal families & $206(62)$ & 0.19 & 0.002 \\
\hline - Additional adjustment for subtype/syndrome ${ }^{\mathrm{b}}$ & & 0.15 & 0.01 \\
\hline
\end{tabular}

${ }^{\mathrm{a}}$ Likelihood ratio test

${ }^{\mathrm{b}}$ For list of the epilepsy syndromes/subtypes within generalized and focal epilepsies, see

Table 1 and Methods. 
Table 3. Analysis of apparent anticipation effect in parent-child pairs. Pairs are "comparable" when both members' age at last observation is older than both members' onset age. The hypothesis that the difference in age at onset within each pair (Onset $t_{\text {parent }}-$ Onset $\left._{\text {child }}\right)$ is greater than zero was tested within a mixed-effects model to account for multiple observations within families.

\begin{tabular}{lcccc} 
Pair type & N of pairs & $\begin{array}{c}\Delta \text { onset age in yrs, } \\
\text { mean }(95 \% \mathrm{CI})\end{array}$ & t-value & p-value \\
\hline All pairs & 287 & $6.4(4.6,8.2)$ & 6.9 & $<0.0001$ \\
"Comparable" pairs & 217 & $2.3(1.0,3.5)$ & 3.7 & 0.0003 \\
\hline
\end{tabular}


Supplementary Table: Epi4K Consortium collaborators

\begin{tabular}{|c|c|}
\hline Author & Affiliation \\
\hline Bassel Abou-Khalil & $\begin{array}{l}\text { Department of Neurology, Vanderbilt University Medical } \\
\text { Center, Nashville, Tennessee } 37232 \text { USA. }\end{array}$ \\
\hline Zaid Afawi & $\begin{array}{l}\text { Sackler School of Medicine, Tel Aviv University, Ramat Aviv, } \\
\text { Israel. }\end{array}$ \\
\hline Andrew S. Allen & $\begin{array}{l}\text { Center for Human Genome Variation, Duke University School } \\
\text { of Medicine, Durham, North Carolina 27708, USA. }\end{array}$ \\
\hline Jocelyn F. Bautista & $\begin{array}{l}\text { Department of Neurology, Cleveland Clinic Lerner College of } \\
\text { Medicine \& Epilepsy, Center of the Cleveland Clinic } \\
\text { Neurological Institute, Cleveland, Ohio } 44195 \text { USA. }\end{array}$ \\
\hline Susannah T. Bellows & $\begin{array}{l}\text { Epilepsy Research Centre, Department of Medicine, University } \\
\text { of Melbourne (Austin Health), Heidelberg, Victoria 3084, } \\
\text { Australia. }\end{array}$ \\
\hline Samuel F. Berkovic & $\begin{array}{l}\text { Epilepsy Research Centre, Department of Medicine, University } \\
\text { of Melbourne (Austin Health), Heidelberg, Victoria 3084, } \\
\text { Australia. }\end{array}$ \\
\hline Judith Bluvstein & $\begin{array}{l}\text { NYU Comprehensive Epilepsy Center, New York University, } \\
\text { Department of Neurology, NYU School of Medicine, New } \\
\text { York, New York 10016, USA. }\end{array}$ \\
\hline Rosemary Burgess & $\begin{array}{l}\text { Epilepsy Research Centre, Department of Medicine, University } \\
\text { of Melbourne (Austin Health), Heidelberg, Victoria 3084, } \\
\text { Australia. }\end{array}$ \\
\hline Gregory D. Cascino & $\begin{array}{l}\text { Division of Epilepsy, Mayo Clinic, Rochester, Minnesota } 55905 \\
\text { USA. }\end{array}$ \\
\hline Patrick Cossette & $\begin{array}{l}\text { Centre of Excellence in Neuromics and CHUM Research } \\
\text { Center, Université de Montréal, CHUM-Hôpital, Notre-Dame } \\
\text { Montréal, Quebec H2L 4M1, Canada. }\end{array}$ \\
\hline Sabrina Cristofaro & $\begin{array}{l}\text { NYU Comprehensive Epilepsy Center, New York University, } \\
\text { Department of Neurology, NYU School of Medicine, New } \\
\text { York, New York 10016, USA. }\end{array}$ \\
\hline Douglas E. Crompton & $\begin{array}{l}\text { Epilepsy Research Centre, Department of Medicine, University } \\
\text { of Melbourne (Austin Health), Heidelberg, Victoria 3084, } \\
\text { Australia. }\end{array}$ \\
\hline Norman Delanty & $\begin{array}{l}\text { Department of Neurology, Beaumont Hospital, and FutureNeuro } \\
\text { Research Centre, Royal College of Surgeons in Ireland, Dublin } \\
\text { 9, Ireland. }\end{array}$ \\
\hline Orrin Devinsky & $\begin{array}{l}\text { NYU Comprehensive Epilepsy Center, New York University, } \\
\text { Department of Neurology, NYU School of Medicine, New } \\
\text { York, New York 10016, USA. }\end{array}$ \\
\hline Dennis Dlugos & $\begin{array}{l}\text { Department of Neurology and Pediatrics, The Children's } \\
\text { Hospital of Philadelphia, Perelman School of Medicine at the }\end{array}$ \\
\hline
\end{tabular}




\begin{tabular}{|c|c|}
\hline & $\begin{array}{l}\text { University of Pennsylvania, Philadelphia, Pennsylvania 19104, } \\
\text { USA. }\end{array}$ \\
\hline Colin A. Ellis & $\begin{array}{l}\text { Epilepsy Research Centre, Department of Medicine, University } \\
\text { of Melbourne (Austin Health), Heidelberg, Victoria 3084, } \\
\text { Australia.; and 11. Department of Neurology, Perelman School } \\
\text { of Medicine at the University of Pennsylvania, Philadelphia, } \\
\text { Pennsylvania 19104, USA. }\end{array}$ \\
\hline Michael P. Epstein & $\begin{array}{l}\text { Department of Human Genetics, Emory University School of } \\
\text { Medicine, Atlanta, Georgia, 30322, USA. }\end{array}$ \\
\hline Nathan B. Fountain & $\begin{array}{l}\text { FE Dreifuss Comprehensive Epilepsy Program, University of } \\
\text { Virginia, Charlottesville, Virginia } 22908 \text { USA. }\end{array}$ \\
\hline Catharine Freyer & $\begin{array}{l}\text { Department of Neurology, University of California, San } \\
\text { Francisco, San Francisco, California } 94143 \text { USA. }\end{array}$ \\
\hline Eric B. Geller & $\begin{array}{l}\text { Institute of Neurology and Neurosurgery at Saint Barnabas, } \\
\text { Saint Barnabas Medical Center, Livingston NJ, USA. }\end{array}$ \\
\hline Tracy Glauser & $\begin{array}{l}\text { Division of Neurology, Cincinnati Children's Hospital Medical } \\
\text { Center, Cincinnati, Ohio } 45229 \text { USA. }\end{array}$ \\
\hline Simon Glynn & $\begin{array}{l}\text { Department of Neurology and Neuroscience Graduate Program, } \\
\text { University of Michigan Medical Center, Ann Arbor, and Ann } \\
\text { Arbor Veterans Administration Healthcare System, Ann Arbor, } \\
\text { Michigan, USA. }\end{array}$ \\
\hline $\begin{array}{l}\text { Hadassa Goldberg- } \\
\text { Stern }\end{array}$ & $\begin{array}{l}\text { Epilepsy Unit, Schneider Children’s Medical Center of Israel, } \\
\text { Petach Tikvah, Israel. }\end{array}$ \\
\hline David B. Goldstein & $\begin{array}{l}\text { Institute for Genomic Medicine, Columbia University Medical } \\
\text { Center, New York, New York } 10032 \text { USA. }\end{array}$ \\
\hline Micheline Gravel & $\begin{array}{l}\text { Centre of Excellence in Neuromics and CHUM Research } \\
\text { Center, Université de Montréal, CHUM-Hôpital, Notre-Dame } \\
\text { Montréal, Quebec H2L 4M1, Canada. }\end{array}$ \\
\hline Kevin Haas & $\begin{array}{l}\text { Department of Neurology, Vanderbilt University Medical } \\
\text { Center, Nashville, Tennessee } 37232 \text { USA. }\end{array}$ \\
\hline Sheryl Haut & $\begin{array}{l}\text { Department of Neurology, Montefiore Einstein, } 111 \text { East 210th } \\
\text { St, Bronx, NY } 1046 .\end{array}$ \\
\hline Erin L. Heinzen & $\begin{array}{l}\text { Institute for Genomic Medicine, Columbia University Medical } \\
\text { Center, New York, New York } 10032 \text { USA. }\end{array}$ \\
\hline Olivia J. Henry & $\begin{array}{l}\text { Epilepsy Research Centre, Department of Medicine, University } \\
\text { of Melbourne (Austin Health), Heidelberg, Victoria 3084, } \\
\text { Australia. }\end{array}$ \\
\hline Heidi E. Kirsch & $\begin{array}{l}\text { Department of Neurology, University of California, San } \\
\text { Francisco, San Francisco, California } 94143 \text { USA. }\end{array}$ \\
\hline Sara Kivity & $\begin{array}{l}\text { Epilepsy Unit, Schneider Children’s Medical Center of Israel, } \\
\text { Petach Tikvah, Israel. }\end{array}$ \\
\hline Robert Knowlton & $\begin{array}{l}\text { Department of Neurology, University of California, San } \\
\text { Francisco, San Francisco, California } 94143 \text { USA. }\end{array}$ \\
\hline
\end{tabular}




\begin{tabular}{|c|c|}
\hline Amos D. Korczyn & $\begin{array}{l}\text { Sackler School of Medicine, Tel Aviv University, Ramat Aviv, } \\
\text { Israel. }\end{array}$ \\
\hline Eric Kossoff & $\begin{array}{l}\text { Department of Neurology, Johns Hopkins Hospital, Baltimore, } \\
\text { Maryland } 21287 \text { USA. }\end{array}$ \\
\hline Ruben Kuzniecky & $\begin{array}{l}\text { Department of Neurology, Zucker Hofstra School of Medicine, } \\
\text { Lenox-Hill Hospital, New York, NY } 10075 .\end{array}$ \\
\hline Rebecca Loeb & $\begin{array}{l}\text { G. H. Sergievsky Center, Columbia University, New York, NY } \\
\text { 10032, USA. }\end{array}$ \\
\hline Daniel H. Lowenstein & $\begin{array}{l}\text { Department of Neurology, University of California, San } \\
\text { Francisco, San Francisco, California } 94143 \text { USA. }\end{array}$ \\
\hline Anthony G. Marson & $\begin{array}{l}\text { Department of Molecular and Clinical Pharmacology, } \\
\text { University of Liverpool, Clinical Sciences Centre, Lower Lane, } \\
\text { Liverpool L9 7LJ, UK. }\end{array}$ \\
\hline Mark McCormack & $\begin{array}{l}\text { Molecular \& Cellular Therapeutics, Royal College of Surgeons } \\
\text { in Ireland, Dublin 2, Ireland; and Department of Genetics, } \\
\text { Universitair Medisch Centrum Utrecht, Utrecht, the } \\
\text { Netherlands. }\end{array}$ \\
\hline Kevin McKenna & $\begin{array}{l}\text { Department of Neurology, University of California, San } \\
\text { Francisco, San Francisco, California } 94143 \text { USA. }\end{array}$ \\
\hline Heather C. Mefford & $\begin{array}{l}\text { Department of Pediatrics, Division of Genetic Medicine, } \\
\text { University of Washington, Seattle, Washington 98195, USA. }\end{array}$ \\
\hline Paul Motika & $\begin{array}{l}\text { Comprehensive Epilepsy Center, Oregon Health and Science } \\
\text { University, Portland, OR } 97239 \text { USA. }\end{array}$ \\
\hline Saul A. Mullen & $\begin{array}{l}\text { Epilepsy Research Centre, Department of Medicine, University } \\
\text { of Melbourne (Austin Health), Heidelberg, Victoria 3084, } \\
\text { Australia. }\end{array}$ \\
\hline Terence J O’Brien & $\begin{array}{l}\text { Departments of Medicine and Neurology, The Royal Melbourne } \\
\text { Hospital, Parkville, Victoria 3146, Australia. }\end{array}$ \\
\hline Ruth Ottman & $\begin{array}{l}\text { G. H. Sergievsky Center, Columbia University, New York, NY } \\
\text { 10032, USA; and Department of Neurology, Columbia } \\
\text { University, New York, NY 10032, USA; and Department of } \\
\text { Epidemiology, Columbia University; and Division of } \\
\text { Translational Epidemiology, New York State Psychiatric } \\
\text { Institute, New York, NY 10032, USA. }\end{array}$ \\
\hline Juliann Paolicchi & $\begin{array}{l}\text { Northeast Regional Epilepsy Group, New York, NY 10017; and } \\
\text { Rutgers University Medical Center, Newark, NJ 07103; and } \\
\text { Seton Hall University Medical Center, Nutley, NJ 07110, USA. }\end{array}$ \\
\hline Jack M. Parent & $\begin{array}{l}\text { Department of Neurology and Neuroscience Graduate Program, } \\
\text { University of Michigan Medical Center, Ann Arbor, and Ann } \\
\text { Arbor Veterans Administration Healthcare System, Ann Arbor, } \\
\text { Michigan, USA. }\end{array}$ \\
\hline Sarah Paterson & $\begin{array}{l}\text { Department of Paediatrics, School of Medicine and Health } \\
\text { Sciences, University of Otago, Wellington, New Zealand. }\end{array}$ \\
\hline
\end{tabular}

Familial epilepsy age at onset - 28

This article is protected by copyright. All rights reserved. 


\begin{tabular}{|c|c|}
\hline Slavé Petrovski & $\begin{array}{l}\text { Epilepsy Research Centre, Department of Medicine, University } \\
\text { of Melbourne (Austin Health), Heidelberg, Victoria 3084, } \\
\text { Australia. }\end{array}$ \\
\hline William Owen Pickrell & $\begin{array}{l}\text { Wales Epilepsy Research Network, Swansea University } \\
\text { Medical School, Swansea University, Wales, UK. }\end{array}$ \\
\hline Annapurna Poduri & $\begin{array}{l}\text { Division of Epilepsy and Clinical Neurophysiology, Department } \\
\text { of Neurology, Boston Children’s Hospital, Boston, } \\
\text { Massachusetts 02115, USA. }\end{array}$ \\
\hline Mark I. Rees & $\begin{array}{l}\text { Wales Epilepsy Research Network, Swansea University } \\
\text { Medical School, Swansea University, Wales, UK. }\end{array}$ \\
\hline Lynette G. Sadleir & $\begin{array}{l}\text { Department of Paediatrics and Child Health, University of } \\
\text { Otago, Wellington, New Zealand. }\end{array}$ \\
\hline Ingrid E. Scheffer & $\begin{array}{l}\text { Epilepsy Research Centre, Department of Medicine, University } \\
\text { of Melbourne (Austin Health), Heidelberg, Victoria 3084, } \\
\text { Australia; and Florey Institute and Department of Paediatrics, } \\
\text { Royal Children's Hospital, Melbourne, Victoria, Australia. }\end{array}$ \\
\hline Jerry Shih & $\begin{array}{l}\text { Comprehensive Epilepsy Center, Department of Neurosciences, } \\
\text { University of California, San Diego School of Medicine, San } \\
\text { Diego, California, USA. }\end{array}$ \\
\hline Rani Singh & Carolinas Health Care System, USA. \\
\hline Joseph Sirven & $\begin{array}{l}\text { Department of Neurology, Mayo Clinic, Scottsdale, Arizona } \\
85259 \text { USA. }\end{array}$ \\
\hline Michael C. Smith & $\begin{array}{l}\text { Rush University Medical Center, Rush Epilepsy Center, } \\
\text { Chicago, IL. }\end{array}$ \\
\hline Phil E.M. Smith & $\begin{array}{l}\text { Department of Neurology, University Hospital of Wales, Heath } \\
\text { Park, Cardiff, Wales, CF14 4XW, UK. }\end{array}$ \\
\hline Liu Lin Thio & $\begin{array}{l}\text { Department of Neurology, Washington University School of } \\
\text { Medicine, St. Louis, Missouri } 63110 \text { USA. }\end{array}$ \\
\hline Rhys H. Thomas & $\begin{array}{l}\text { Epilepsy Research Centre, Department of Medicine, University } \\
\text { of Melbourne (Austin Health), Heidelberg, Victoria 3084, } \\
\text { Australia.; and Wales Epilepsy Research Network, Swansea } \\
\text { University Medical School, Swansea University, Wales, UK; } \\
\text { and MRC Centre for Neuropsychiatric Genetics \& Genomics, } \\
\text { Cardiff University, Wales, CF24 4HQ, UK. }\end{array}$ \\
\hline Anu Venkat & $\begin{array}{l}\text { Department of Pediatrics, Children’s Hospital at Saint Peter’s } \\
\text { University Hospital, Rutgers Robert Wood Johnson Medical } \\
\text { School, New Brunswick, NJ, USA. }\end{array}$ \\
\hline Eileen Vining & $\begin{array}{l}\text { Department of Neurology, Johns Hopkins Hospital, Baltimore, } \\
\text { Maryland } 21287 \text { USA. }\end{array}$ \\
\hline Gretchen Von Allmen & $\begin{array}{l}\text { Division of Child \& Adolescent Neurology, Departments of } \\
\text { Pediatrics, University of Texas Medical School, Houston, Texas } \\
77030 \text { USA. }\end{array}$ \\
\hline Judith Weisenberg & Department of Neurology, Washington University School of \\
\hline
\end{tabular}

Familial epilepsy age at onset - 29

This article is protected by copyright. All rights reserved. 


\begin{tabular}{|l|l|}
\hline & Medicine, St. Louis, Missouri 63110 USA. \\
\hline Peter Widdess-Walsh & Department of Neurology, Beaumont Hospital, Dublin, Ireland. \\
\hline & G. H. Sergievsky Center, Columbia University, New York, NY \\
& 10032, USA; and Department of Neurology, Columbia \\
Melodie R. Winawer & University, New York, NY 10032, USA. \\
\hline
\end{tabular}

Familial epilepsy age at onset - 30

This article is protected by copyright. All rights reserved. 


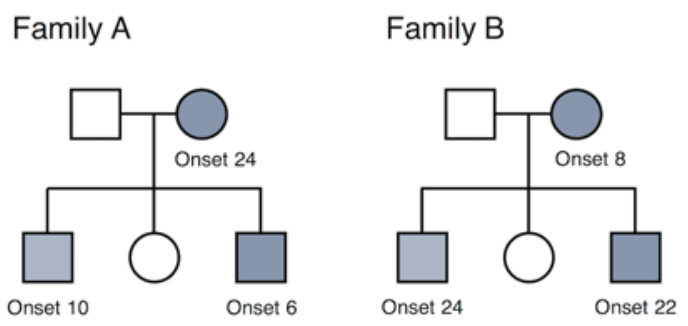

Familial epilepsy age at onset - 31 This article is protected by copyright. All rights reserved. 
A

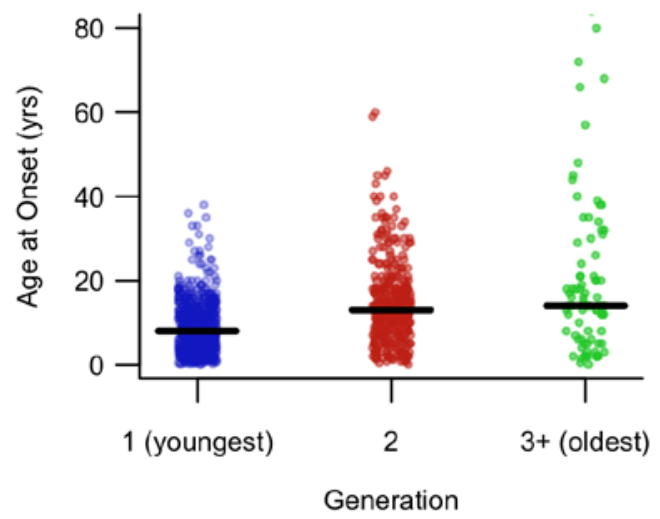

B

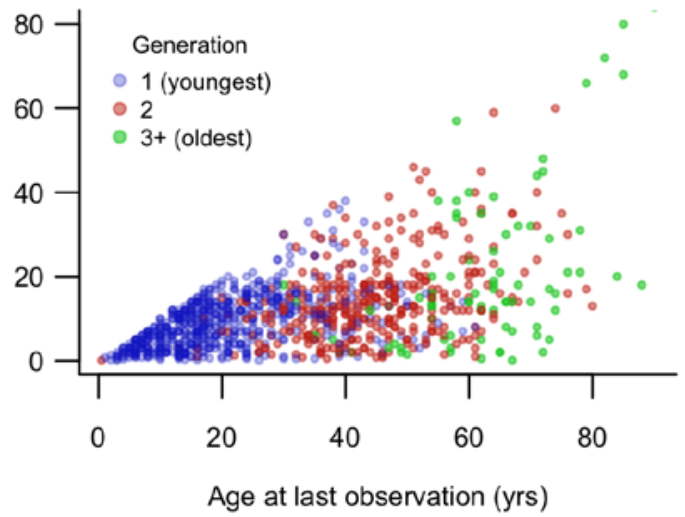

Familial epilepsy age at onset - 32

This article is protected by copyright. All rights reserved. 


\section{Please wait...}

If this message is not eventually replaced by the proper contents of the document, your PDF viewer may not be able to display this type of document.

You can upgrade to the latest version of Adobe Reader for Windows®, Mac, or Linux® by visiting http://www.adobe.com/go/reader_download.

For more assistance with Adobe Reader visit http://www.adobe.com/go/acrreader.

Windows is either a registered trademark or a trademark of Microsoft Corporation in the United States and/or other countries. Mac is a trademark
of Apple Inc., registered in the United States and other countries. Linux is the registered trademark of Linus Torvalds in the U.S. and other countries. 


\section{Please wait...}

If this message is not eventually replaced by the proper contents of the document, your PDF viewer may not be able to display this type of document.

You can upgrade to the latest version of Adobe Reader for Windows®, Mac, or Linux® by visiting http://www.adobe.com/go/reader_download.

For more assistance with Adobe Reader visit http://www.adobe.com/go/acrreader.

Windows is either a registered trademark or a trademark of Microsoft Corporation in the United States and/or other countries. Mac is a trademark
of Apple Inc., registered in the United States and other countries. Linux is the registered trademark of Linus Torvalds in the U.S. and other countries. 


\section{Please wait...}

If this message is not eventually replaced by the proper contents of the document, your PDF viewer may not be able to display this type of document.

You can upgrade to the latest version of Adobe Reader for Windows®, Mac, or Linux® by visiting http://www.adobe.com/go/reader_download.

For more assistance with Adobe Reader visit http://www.adobe.com/go/acrreader.

Windows is either a registered trademark or a trademark of Microsoft Corporation in the United States and/or other countries. Mac is a trademark
of Apple Inc., registered in the United States and other countries. Linux is the registered trademark of Linus Torvalds in the U.S. and other countries. 


\section{Please wait...}

If this message is not eventually replaced by the proper contents of the document, your PDF viewer may not be able to display this type of document.

You can upgrade to the latest version of Adobe Reader for Windows®, Mac, or Linux® by visiting http://www.adobe.com/go/reader_download.

For more assistance with Adobe Reader visit http://www.adobe.com/go/acrreader.

Windows is either a registered trademark or a trademark of Microsoft Corporation in the United States and/or other countries. Mac is a trademark
of Apple Inc., registered in the United States and other countries. Linux is the registered trademark of Linus Torvalds in the U.S. and other countries. 


\section{Please wait...}

If this message is not eventually replaced by the proper contents of the document, your PDF viewer may not be able to display this type of document.

You can upgrade to the latest version of Adobe Reader for Windows®, Mac, or Linux® by visiting http://www.adobe.com/go/reader_download.

For more assistance with Adobe Reader visit http://www.adobe.com/go/acrreader.

Windows is either a registered trademark or a trademark of Microsoft Corporation in the United States and/or other countries. Mac is a trademark
of Apple Inc., registered in the United States and other countries. Linux is the registered trademark of Linus Torvalds in the U.S. and other countries. 


\section{Please wait...}

If this message is not eventually replaced by the proper contents of the document, your PDF viewer may not be able to display this type of document.

You can upgrade to the latest version of Adobe Reader for Windows®, Mac, or Linux® by visiting http://www.adobe.com/go/reader_download.

For more assistance with Adobe Reader visit http://www.adobe.com/go/acrreader.

Windows is either a registered trademark or a trademark of Microsoft Corporation in the United States and/or other countries. Mac is a trademark
of Apple Inc., registered in the United States and other countries. Linux is the registered trademark of Linus Torvalds in the U.S. and other countries. 
A

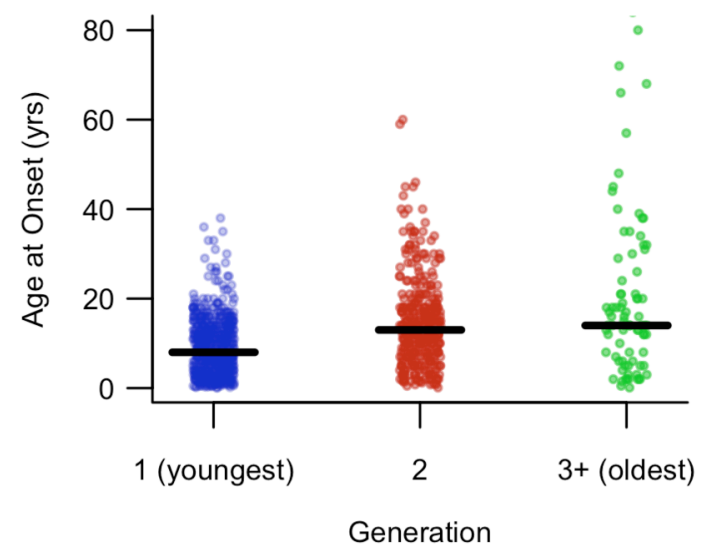

B

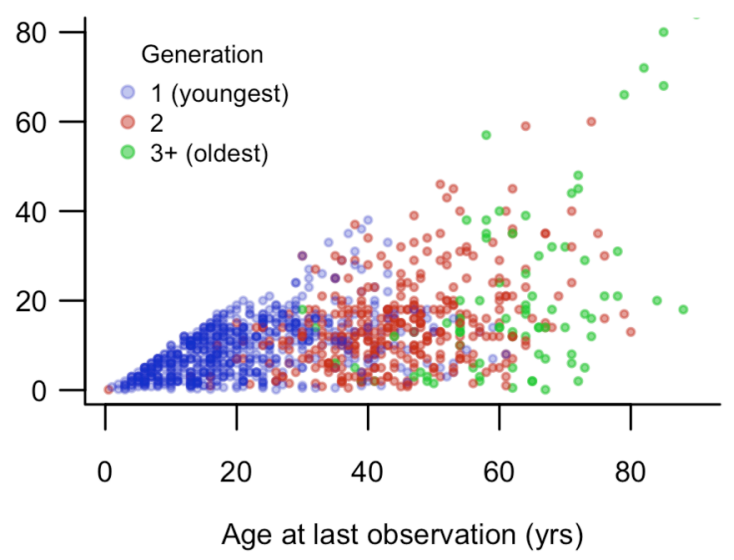

ANA_25499_Figure1revised.tiff

This article is protected by copyright. All rights reserved. 


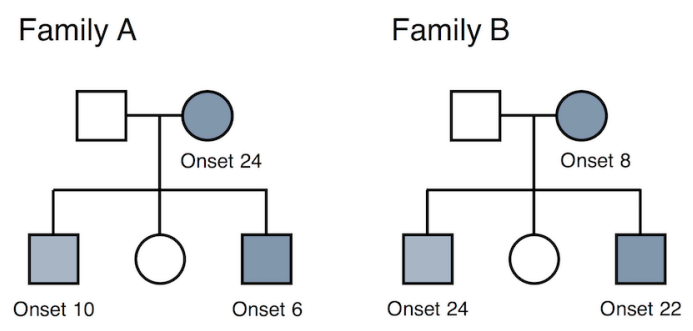

ANA_25499_Figure 2.tiff

This article is protected by copyright. All rights reserved. 


\section{Please wait...}

If this message is not eventually replaced by the proper contents of the document, your PDF viewer may not be able to display this type of document.

You can upgrade to the latest version of Adobe Reader for Windows®, Mac, or Linux® by visiting http://www.adobe.com/go/reader_download.

For more assistance with Adobe Reader visit http://www.adobe.com/go/acrreader.

Windows is either a registered trademark or a trademark of Microsoft Corporation in the United States and/or other countries. Mac is a trademark
of Apple Inc., registered in the United States and other countries. Linux is the registered trademark of Linus Torvalds in the U.S. and other countries. 


\section{University Library}

\section{- M M N E R VA A gateway to Melbourne's research publications}

Minerva Access is the Institutional Repository of The University of Melbourne

Author/s:

Ellis, CA;Churilov, L;Epstein, MP;Xie, SX;Bellows, ST;Ottman, R;Berkovic, SF

Title:

Epilepsy in families: Age at onset is a familial trait, independent of syndrome

Date:

2019-07-01

Citation:

Ellis, C. A., Churilov, L., Epstein, M. P., Xie, S. X., Bellows, S. T., Ottman, R. \& Berkovic, S. F. (2019). Epilepsy in families: Age at onset is a familial trait, independent of syndrome. ANNALS OF NEUROLOGY, 86 (1), pp.91-98. https://doi.org/10.1002/ana.25499.

Persistent Link:

http://hdl.handle.net/11343/285877 